\title{
The Application of the Split Class Model in the Course of Psychological Research Methods
}

\section{Tan Hongxiu}

\author{
Shaoguan university, Education School, Guangdong Shaoguan, 512005, China
}

Keywords: classrooms; psychological research methods

\begin{abstract}
: the teaching mode of "divided classroom" has been carried out in the examination oriented education of many colleges and universities. The scientific and staged lecture form that is innovative and able to interact with teachers and students has been applied to many fields of teaching. By studying the specific application of the divided classroom mode in the psychological research method course, this paper finds out the problems existing in the classroom teaching mode in the psychological research method course, and finds the way to solve the problem. The purpose of the study is to help college psychology research to guide students better through advanced teaching models [1].
\end{abstract}

\section{Preface}

The teaching mode of divided classroom is first proposed by Professor Zhang Xuexin. Its core idea is summarized by PAD three letters. The meaning of these three letters is Presentation, Assimilation and Discussion respectively. This is a teacher and students discuss in the teaching mode combine together, different from the traditional teacher-student participation pattern is the middle for some time so that students will learn the knowledge, so that students can be fully prepared to make the next teaching discussion more investment, and improve the learning enthusiasm the students' initiative and improve. The application of the model in the classroom is also of profound significance in the course of psychology [2].

\section{The specific application of the split class model in the course of psychological research methods}

The classroom teaching mode is widely applied in many professions, such as mathematics, Chinese politics, English or some major courses such as finance, economics and so on. But the application of psychological research methods is not very much, because traditional psychological research pays more attention to theoretical knowledge and specific analysis of specific cases. These learning independence is strong, and there is no need for too many teacher-student communication or collective participation. The earliest classrooms came from Harvard University in the United States. After that, Professor Zhang Xuexin first proposed and tested the teaching mode of the two classrooms in the compulsory course of psychological research methods and experiments in Fudan University. The whole teaching process is divided into three parts. The first part is the traditional class teaching. The second part is the homework assignment and the revision plan. The third part organizes the student to carry on the exchange study, through group discussion and teacher student discussion pattern. Finally, the results of the survey show that the response is good among the students, and the students agree with each other [3].

The classroom teaching of psychological research courses is usually done in a weekly unit, and each week completes a fixed theoretical study and group discussion learning. Theoretical learning includes two hours of knowledge instruction and consolidation review, followed by an hour's discussion course. This scientific and effective curriculum model can not only achieve the objective of students' subjective learning, but also enable students to make faster progress through communication.

For students who first contact with psychology courses, the classroom teaching mode is usually 
done through teachers' teaching content and text and video data in actual cases. In class, teachers can impart knowledge to students, and inform students to integrate their knowledge in the form of homework, and set up a discussion and study class, so that students can participate in the speech, ask questions and solve problems. The teaching mode in the classrooms improves the status of the traditional classroom students who do not study carefully and speak too little [4].

The assessment system on the classroom in the study of psychology in the teaching mode, in addition to the traditional form of assessment work, and participate in the speech group discussion will be credited to the usual results, thus, can stimulate the students take the initiative to learn, and actively participate in the discussion and exchange in. Because the psychology course is not only a simple psychological knowledge teaching, it involves a wide range of content, is an interesting and profound subject. By dividing classroom, we can make this discipline closer to student's life and find resonance from life, so as to stimulate students' learning enthusiasm, and use what they learn to explain the events that happen in their lives.

The duer classroom uses the original boring psychology research course, through scientific teaching mode, to assist students to learn, so that students can understand the connotation and realistic significance of psychology more easily. From cognition, communication to summary, students can better learn the course of psychology, "the relationship between human behavior and psychological activity". The students agree that the teaching model in the sub class has strengthened its basic knowledge and opened up its own vision. They agree with the teaching model.

\section{The problems in the course of the division of classroom in the course of psychological research methods}

Psychology is a complex specialty, which includes the major disciplines such as "psychology statistics" and "psychometrics". Therefore, there are some teachers who react. There are some special problems in the application of the classroom teaching mode in professional psychology teaching.

The traditional teaching of teachers, it is difficult in a short time will be the core concept into reality on the classroom teaching, because psychology is a theoretical subject, which includes the calculation of reliability and validity, error theory, mathematical statistics principle formula, and contains a large number of professional terminology and concepts to abstract rote. Therefore, teachers will still focus on Teaching in theoretical teaching. But the science of classroom lectures and group discussions on the time allocation strictly, but some teachers in the lecture part is no good for students interested in or the corresponding knowledge can not be carried out on the next classroom teaching, teaching will feel greater pressure, if unable to complete the task of teaching in the classroom no time to talk about the practice of grouping. Learning without communication and practice makes students feel boring and affect their interest in psychological research [5].

Psychological research is a very theoretical discipline. Teachers will use a lot of time to explain theoretical knowledge and calculation methods to students, so teachers' dominance and control will be strong. In this way, teachers should be taken as the main body for classroom teaching, but the students' sense of participation is ignored. The group discussion on many classroom requirements in order to cope with the school just get throught a thing carelessly, it really did not meet the students as the main body of the class to learn to communicate with each other. A lot of discussion class is too boring, the teacher led the students to speak, or compel students to speak, students as a result of the traditional teaching mode can not really let me fly, do the masters of knowledge, still love passive way of teaching, has a great influence on the development of this undoubtedly divided class [6].

The core feature of psychology is the learning process. But in order to complete teaching tasks and national exam oriented education requirements, schools often focus on students' tests. Therefore, teachers will also focus on the point and formula of psychological knowledge, and give students the focus and examination scope before the exam. This undoubtedly limits the knowledge that has been learned, and binds the ability of students to diverge thinking. And only through examination papers can not really know students' comprehensive ability in psychological research. 


\section{Solutions to the problems in the course of the split class in the course of psychological research methods}

The main reason for the problem of the split classroom mode in the psychological research method is that the school did not make strict teaching plan and put it into practice. The sub class teaching program in many schools is only to meet the requirements of the country and has not been truly implemented. In order to improve the school psychology courses teaching plan, the school should carry out on the first classroom teaching in strict accordance with the teaching process, from lectures to review after class to discuss, each link can not be omitted; secondly, each link needs to give students sufficient time, and scientific allocation of each link should occupy the time. Not because the teacher did not complete the task and lectures occupy students' time for free discussion, or because the students in group discussions and summary answering time reduce speak freely; to develop a detailed teaching plan, not only need teachers before class lessons carefully and fully prepared, but also requires teachers to arrange after-school homework to help students to learn the knowledge students, teachers should pay attention to the digestion and absorption of the link, this link has a connecting role, not only can In order to have auxiliary effect on classroom lectures, also can be in the group discussion in the subsequent to enable students to lay a good foundation; at the same time should be set to the corresponding topic set in group discussion before the teacher, and inform the students before class each discussed, each group discussion content from four to five.

Only a complete and scientific teaching system can bring the effect of the sub class into full play. Teachers and students should strictly abide by the teaching plan of the divided classroom and implement it conscientiously. A good teaching model needs to be polished in practice. With the implementation of the teaching plan, teachers and students will benefit from the classroom.

Although the teaching mode in the classrooms has advanced and scientific development prospects, it also follows the characteristics of many traditional teaching models. In practical teaching, teachers and students should constantly optimize this teaching mode, draw a better teaching plan from practice and innovate continuously. The classroom is on the core of students as the main body, let the students have the initiative in the classroom, some students suggested a chapter of psychology curriculum knowledge is divided into two classes, the first class when the teacher taught the book knowledge, students in the after-school review, second classes of first class discussion by the students into groups. The teacher proposed topics for discussion within the group began to debate, the teacher sat in pointing, and by members of the group the result of the debate summarizes and answering questions, finally arrive at the optimal answer to the question; the second sessions of second hours by the teacher to teach the new knowledge. This innovative way optimizes student participation on the basis of sub classrooms, and is more suitable for students' learning rhythm. It breaks through the original instillation teaching from the perspective of students, and enables students to enjoy learning psychology enjoyable.

The difficulty of psychology is to master a certain amount of basic knowledge and calculation methods, so that we can apply it to practice. Therefore, for the innovation of the divided classroom, we should focus on the review and digestion after class discussion. With inductive and divergent homework, students' understanding and creativity can be improved. Teachers should not exercise after class. At the same time, the teacher's summary of the discussion topic scale should be grasped well, and leave the room for the students to express their views. In order to improve the efficiency of the divided classroom, the time of group discussion can be flexibly processed, breaking the established pattern, and after the discussion, teachers can choose the students with clear analysis and clear opinions to summarize the subjects.

Because the split classroom is an innovative and complex mode compared with the traditional teaching mode, so we can't evaluate students' achievement in a single form of examination. Because students' after-school digestion and absorption and group discussion are included in the whole learning process, so the initiative learning ability of students needs to be reflected in the form of achievement, reflecting the process of students' subjective learning. Therefore, schools should conduct comprehensive assessment of homework, group discussion, and final examination in the process of psychological teaching. The three parts should be 1:3:6. This scientific grading means 
that students must be seriously involved in the learning process of psychology, no longer only to deal with the final review of the final exam. The form of test in pairs classroom should match its core teaching idea. We must attach importance to students' participation and subjective learning ability, and put the emphasis of evaluation on students' daily learning.

The new examination mode produced by the sub class not only pays attention to the assessment of ordinary learning but also the form of final examination. For example, to join the interview in the final exam, the number of interview questions by the teacher free distribution, but the topic is daily group discussion covers the contents of the study, and ensure that the interview questions can be investigated to the psychology of the content, spirit and core thought, also need to include a comprehensive analysis of the actual case of psychology. In order to reduce the difficulty of interview and improve the participation of students, the topic of interview examination should be sent to students ahead of time. Each student will allocate five questions immediately, preparing for answers before exams, but asking questions randomly at interviews. The interview teacher can take a face-to-face interview or a telephone interview. If you take a phone interview, you need a full call. The interview time should be controlled within ten to fifteen minutes, the interviewer should in the interview process will focus on the assessment of students' learning ability, try to say as little as possible by the students, the teacher questions, organized by student language and give answers to heart problems. The interview teacher can put forward new questions at the same time with the students' elaboration and help students to divert their thinking.

Psychological courses need not only a large number of theoretical knowledge and calculation methods as the basis, but also the students' careful thinking and analytical abilities. Therefore, the evaluation system should also add comments and guidance from the teachers, summarize the learning state and learning outcomes of every student in this semester, encourage their advantages in learning, and analyze the lack of learning methods. Teachers' summing up should be reflected in the comprehensive score at the end of the term. Teachers can score according to the daily performance of the students, and the full score is quite appropriate.

\section{Conclusion}

Because of the strong theoretical nature of psychology curriculum, the teaching mode should be more scientific and reasonable, and it will solve this problem well by the emergence of sub classroom teaching mode. It not only enables students to learn theoretical knowledge from shallow to deep, but also enables students to improve their understanding of psychological knowledge after class digestion and absorption and group discussion. Although many colleges and universities to carry out the application on the classroom in the course of psychology research methods still exist many problems, but with the continuous improvement of the school teaching plan, teaching model innovation and optimize the examination system, I believe have long-term development on classroom teaching mode in the course of research methods in psychology.

\section{Acknowledgments}

This paper is the research result of 2015 teaching quality and teaching reform project in Guangdong province's undergraduate colleges and universities teaching team of teachers education class” Guangdong high education document[2015]133), key research projects of the 17th education reform in Shaoguan university "Study on the problems and countermeasures of education practice in normal students (Shaoguan universityb2016 72 general research projects of the 17th education reform in Shaoguan university Practice of the PAD class teaching mode in the course of psychology research method”(Shaoguan university[2016]272).

\section{References}

[1] Consciousness D. Dual consciousness (neuroscience)[J].

[2] Bregman L. The Interpreter/Experiencer Split: Three Models in the Psychology of Religion[J]. 
1978, XLVI (2):203.

[3] Fernandez J E. MOTIVATIONAL COACHING TECHNIQUES TAILORED FOR INDIVIDUALS, US20080280277[P]. 2008.

[4] Ross S, Ginsburg B E, Denenberg V H. The use of the split-litter technique in psychological research[J]. Psychological Bulletin, 1957, 54(2):145.

[5] Diana J. Schwerha. Impact of auditory and visual distractors upon learning a manual assembly task in older workers[J]. 2004.

[6] Fernandez J E. Motivational coaching techniques tailored for individuals[J]. 2008.

A brief introduction to the author: Tan Hongxiu, Female, Jiangxi province, October 18th, 1977. Master degree, cognitive psychology 